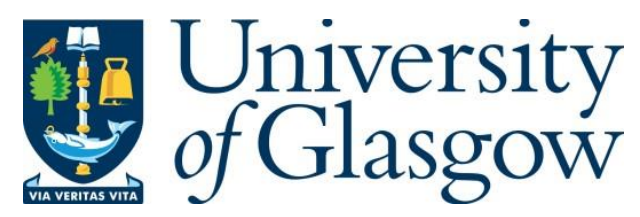

Maguire, J. and Draper, S. (2022) Promoting Engagement in Remote Computing Ethics Education. Computing Education Practice 2022 (CEP 2022), Durham, United Kingdom, 06 Jan 2022. ISBN 9781450395618

There may be differences between this version and the published version. You are advised to consult the publisher's version if you wish to cite from it.

(C) 2022 Association for Computing Machinery. This is the author's version of the work. It is posted here for your personal use. Not for redistribution. The definitive Version of Record was published in CEP 2022: Computing Education Practice 2022 http://dx.doi.org/10.1145/3498343.3498345

http://eprints.gla.ac.uk/261029/

Deposited on: 15 December 2021

Enlighten - Research publications by members of the University of Glasgow http://eprints.gla.ac.uk 


\section{Promoting Engagement in Remote Computing Ethics Education}

\author{
Joseph Maguire \\ School of Computing Science \\ University of Glasgow \\ Glasgow, Scotland, United Kingdom \\ joseph.maguire@glasgow.ac.uk
}

\author{
Steve Draper \\ School of Psychology \\ University of Glasgow \\ Glasgow, Scotland, United Kingdom \\ steve.draper@glasgow.ac.uk
}

\begin{abstract}
Remote delivery of course content was a rapid and practical solution to the challenges presented to education by the coronavirus pandemic. However, the solution also provided the opportunity to promote engagement and interaction among a student cohort that was largely disconnected and isolated due to the constraints of the pandemic. Consequently, in this paper the practice of using the Jigsaw active learning design in the delivery of a computing ethics course is reported. The experience, reaction of learners and discussion of the benefits and problems of the learning design are discussed before concluding thoughts are offered.
\end{abstract}

\section{CCS CONCEPTS}

- Social and professional topics $\rightarrow$ Codes of ethics;

\section{KEYWORDS}

computing education, ethics, active learning, jigsaw

\section{ACM Reference Format:}

Joseph Maguire and Steve Draper. 2022. Promoting Engagement in Remote Computing Ethics Education. In Computing Education Practice 2022 (CEP 2022), January 6, 2022, Durham, United Kingdom. ACM, New York, NY, USA, 4 pages. https://doi.org/10.1145/3498343. 3498345

\section{INTRODUCTION}

The coronavirus pandemic presented problems for students and educators alike. Challenges for educators were that well established and practiced teaching methods, such as in-person lectures, became problematic. Challenges for students were being isolated, and separated from the typical social interaction they would experience at university [5]. This is important both socially, and from the educationally valuable peer interactions about the content they are learning.

CEP 2022, fanuary 6, 2022, Durham, United Kingdom

(c) 2022 Association for Computing Machinery.

This is the author's version of the work. It is posted here for your personal use. Not for redistribution. The definitive Version of Record was published in Computing Education Practice 2022 (CEP 2022), January 6, 2022, Durham, United Kingdom, https://doi.org/10.1145/3498343.3498345.
Nevertheless, the pandemic also presented opportunities for educators to explore novel learning designs that could potentially support students in attaining deeper engagement with both course content and peers. The present paper presents the use of an active learning practice on a computing ethics course. The lessons learned from the experience of adopting the active learning practice serve as a valuable contribution to educators in asking themselves key questions when deploying relatively novel teaching practices.

Consequently, the contributions of this paper are:

- Design of an active learning practice with approximately 200 students.

- Discussion of the experience and challenges encountered by students engaged with the practice.

\section{BACKGROUND}

Lectures are the dominant teaching method in universities across the United Kingdom and emerged in an age where information was not only difficult to produce but also to transmit [3]. Active learning practices in particular, where students collaborate and engage in content, could be effective in not only supporting students to engage with content to a greater depth, but could also enrich their learning experience at a challenging time [11]. The challenge with active learning practices in computing science and more broadly is that there is little agreement on the definition or the effectiveness of them [12]. Nevertheless, active learning practices have been used in many different contexts and have been found to be engaging and stimulating, at least from a social perspective [10].

Kothiyal et al. report use of the think-pair-share active learning practice with a computing science cohort, where students consider a problem posed privately, then partner with peers to refine, all prior to engaging in a class discussion [8]. They report strong student engagement with the thinking and sharing aspects, but less so with the pairing element.

Jigsaw, where students collaborate rather than compete is another active learning approach. Aronson et al. originally proposed the approach in the 1970s as a way to address conflicts and challenges around desegregation in classrooms in 
the United States [2]. The approach is elaborate compared to many teaching practices, but has been shown to be effective in some respects. Honeychurch reports use of the approach with a small first year philosophy cohort and argues students were able to cover considerable material in a short space of time and the feedback from peers was valuable in engaging with course content [7]. Similarly, Liao et al. reports use of the approach on a computer architecture course where students report greater engagement with course material [9]. Consequently, utilising the Jigsaw active learning practice might be an effective way for students not only to engage with a wide range of material, but to do so collectively at a stressful, isolating time.

\section{CONTEXT}

Here we report our experience of using a Jigsaw active learning design on a Professional Skills and Issues course with approximately 200 senior undergraduates and a small number of postgraduates. The course is compulsory for undergraduates and is taken alongside seven other courses that students have elected to do. The course is offered as an elective for postgraduate students. The aim of the course is to engage students with ethical issues relevant to computing science and software engineering professionals as well as to provide students an opportunity to refine communication skills. The course covers four subject areas: society and surveillance, profits and platforms, risk and responsibility, decisions and discrimination. The course also provides practice for students at verbal and written work and so advances their communication skills.

\section{LEARNING DESIGN}

The course covers four subjects, each delivered over a two week teaching-block with four timetabled hours. Each subject has a reading list of six items, each of which could be a research paper, article, video or audio recording. Each subject is delivered using the Jigsaw learning design.

The fundamental difference between a Jigsaw design and conventional teaching is that the learners, not the teacher, function as subject matter experts and the source of knowledge for other students. The important difference between Jigsaw and other methods of group work is that each learner is a member of two different, cross-cutting, groups: a jigsaw group for reciprocal teaching (sharing their partial knowledge with others who know different bits of knowledge), and an expert (colour) group for preparing the teaching each must do in their other (jigsaw) group. In assigning a student to an expert group, the student is assigned to only one of the six resources for the subject. Each student is assigned a colour (one of six) which specifies which expert group they are a member of, and a number specifying which jigsaw (crossteaching) group they are a member of. Both jigsaw and expert groups typically had six group members.

For each teaching block, the four hours were structured for students. Students were advised to spend the first hour engaging with material from the subject reading list. Then, for the second hour, the students should meet their expert group for one hour. For the third hour in the block, students should meet their jigsaw group. And lastly for the fourth and final hour of the block students were required to attend a seminar with the lecturer. The one-hour seminar was scheduled via the University timetable as were the other hours in the block. However, students could do their group meetings at other times that were preferable to each group if they so wished.

Therefore, in practice, a student started by engaging with the content on the reading list that matched the colour assigned to them. Then, in their expert group spent no more than 10 minutes outlining the salient aspects of it, before other members performed the same action. The expert group then nominated a scribe, agreed a summary of all the presentations and the scribe added the summary to the course wiki. Then each student, in their jigsaw group spent no more than 10 minutes presenting the summary generated at their expert group, before other members performed the same action. The last step was for students to attend the seminar led by the lecturer. The lecturer presented an unseen scenario which the class tackled using the knowledge already discussed. The class considered the problem for 10 minutes, then the lecturer spent 10 minutes going over the scenario and highlighting important lessons to be taken from it. Then, another scenario was presented for 10 minutes, drawn from case studies developed by Anderson et al. for the ACM Code of Ethics and Professional Conduct [1]. The lecturer then polled the class for thoughts and closed the class by summarising key points and addressing any misconceptions.

\section{RESULTS}

Students were asked to complete a standard survey at the end of the course that probed overall experience and offered an opportunity to provide open-text comments on the strengths and weaknesses of the course. Approximately 200 students were enrolled on the course with 73 students providing feedback. Participation in the survey was anonymous, and feedback from individual students is referred to by a random identification number, e.g. "S18".

The feedback from students on course material and content, such as videos, lectures and reading material, was generally positive. Students felt the material was engaging and interesting, as reflected in the feedback received from them. The comment from S54 reflected the feedback of many students when it came to the course content material, "material 
was interesting and thought-provoking at times". Similarly, S19 stated "I thoroughly enjoyed the content of the course. I had some great discussions with other students and the lecturer during Zoom breakout sessions". Nevertheless, course material and content was not the aspect of the course that generated the most feedback, neither was it the concern that drew the most notable differences in opinion.

Such feedback was reserved for the learning design and delivery of the course with the majority of student feedback being negative towards the experience. Consequently, the remainder of the results section considers feedback pertaining to the learning design and delivery, in terms of the good, the bad and the ugly feedback.

The good feedback. There appeared to be some recognition that students appreciated the social aspects of the learning design in terms of engaging and interacting with other students on the course, as reflected by S24 "liked that we had contact with people I've never met in the course before". The motivation, in part, in selecting the Jigsaw learning design was to ensure students had some engagement with each other and were not always engaged in isolated tasks during the pandemic. This aspect of the learning design was appreciated by some students as noted by S34 "the group work allowed some natural interaction with people when isolated". Another aspect of the learning design that was anticipated to be a strength was that students would be able to engage with a greater breadth and depth of content with the learning design than they would on a traditionally structured course. Students appeared to appreciate this aspect of the learning design with S38 reflecting the majority of such positive feedback by stating "resources are varied, 'pooling' of knowledge across groups is a good idea".

The bad feedback. The learning design was more complex than typical teaching approaches. However, it is clear that many students felt the design was not only complex, but unnecessarily so, in that the challenge was not to understand what action to perform, but that such actions provided little benefit as reflected by S65 "reduce the unnecessary complexity of sub group this, colour group this, number group that". An immediate reaction to such feedback by a lecturer could be that such feedback is explained due to unfamiliarity with the learning design and active learning pedagogical practices in general.

However, some feedback did indicate that students had an awareness or experience of such pedagogical practices, since some students mentioned "flipped classroom" in feedback comments as exemplified by feedback from S19, "We very much dislike the flipped classroom model. The structure class colour/division/class group/expert group/presentation group was just confusing". The "flipped classroom" was not a phrase used by the course coordinator nor any course material and its presence in feedback suggests some student awareness of active learning practices.

The virtual learning environment (VLE), Moodle, was used as the main delivery platform for the course with instructions, activities and content delivered through the platform. Students had used the platform for several years at this point and the assumption had been that it would not present any challenges. However, some students clearly felt the platform did not support delivery of the learning design or the course as reflected by S10 "prior courses in the university have never had such a strong focus on Moodle content so the jump to using that was very strange. Accessing relevant information is extremely difficult. The course had so many moving parts and it was difficult to discern what was happening - lecture material and information is not easily accessible".

The ugly feedback. The reality is that while there may be strengths to this learning design, the delivery and execution of the approach in this context were not widely perceived as positive by all students. Ugly feedback is negative in nature but also uncomfortable for lecturers as it probably highlights significant frustrations with aspects of the course. It is clear that some students found the complexity of the learning design challenging and frustrating in contrast to traditional courses where students attend regular lectures. The Jigsaw design not only required students to communicate with several groups, but to move between them and communicate outcomes from them. This level of complexity was perceived negatively by many students and is reflected in feedback from S15, "In the very first meeting for the course a student humorously asked why the course structure resembled a Christopher Nolan film. The difference is that Christopher Nolan films are quite easy to understand the second time you watch them, but this course is still confusing after 10 weeks". Importantly, it should be emphasised that this feedback may be more indicative of how the course structure was communicated, rather than the structure itself. Nevertheless, while one of the central aims of the learning design was to bring students together, it was clear that the design presented a challenge for some students and caused frustration as reflected by S44 with "It certainly brought the student body together, albeit in severe frustration".

Finally, one last element of feedback: the educator's observations of the quality of discussion within the groups, when observing them. This was at times the best quality discussion of any heard previously in different forms of this course.

\section{DISCUSSION}

The two group types in the Jigsaw learning design are of different kinds. The expert groups are like a normal peer discussion, sorting out what is meant to be the same idea amongst students who have some knowledge of it, but do not yet agree and see it the same way. However, figsaw groups 
are about teaching other students as in "student generated content" (SGC), where students create content for other students. SGC was and is present in classical seminars, in which a different student presents each week. But all too often, there is no enforcement of listening to other students' presentations and discussing them. Betty Collis is an authority for more modern and radical forms of SGC [4].

The quality the teacher heard in some of the student discussions shows that the benefits of the method were present, but what explains the negative perceptions of students with the present learning design in its particular context?

It might simply be the teacher's poor explanation of the design to students. It has certainly proved hard to communicate what a Jigsaw design is to a conference audience. But that seems unlikely to be the explanation here because of the success of Jigsaw designs in other cases.

The number of iterations or cycles of the design within one class may be important. Even Mazur's Peer Interaction might not work well in only four iterations in its first use with a class: its widespread success has almost all been in one or two semester long classes, with an iteration of the design at least once a week i.e. 12 iterations or more [6].

Furthermore, in many cases of anonymous student feedback, negative things that were felt at the time are often quite quickly forgotten and so not expressed after things work well for that student for a week or two. In other words the complaints may be about starting up, but not about all phases and aspects of the course design. They are therefore worth fixing if possible, but may not in the end be important for whether or not to adopt a design like this as a whole; they may indicate a conclusion about minimum length of use, not about whether the design is worth adopting at all.

The dislike of students for this implementation of Jigsaw may be a distance learning issue because Jigsaw has worked well even in the first iteration in one big room with groups in different corners. One arena allows both learners and teachers to see the physical group structure and self-correct and get help; and for teachers also to see problems and go fix them.

The amount of prior experience with group work that each student in the class has had might also be a significant factor. On the other hand, Honeychurch's success with Jigsaw [7] in first year undergraduate philosophy undermines that inference yet still suggests that more iterations of the Jigsaw is the key.

\section{LIMITATIONS AND CONCLUSIONS}

The primary limitation of this study is its reliance on openended text feedback from standard course evaluations to understand student reactions to the application of the Jigsaw learning design in this particular context. Such data is not strong enough to assess the effectiveness of the approach in a general way e.g. as a good or bad learning design across all contexts, or as good or bad in computing science contexts. However the feedback data does support a useful and moderately general set of conclusions of a different kind, as follows.

When adopting a learning design involving group work, and especially the Jigsaw design, the educator should:

(1) Consider the students' prior group work experience.

(2) Estimate the minimum number of iterations likely to be required for the design to "bed in".

(3) Decide whether a Jigsaw design (or other form of group work) is likely to work well in the given context.

(4) Plan for the best way to communicate it to students, given their degree of unfamiliarity with each element of the design.

\section{REFERENCES}

[1] Ronald E Anderson, Deborah G Johnson, Donald Gotterbarn, and Judith Perrolle. 1993. Using the new ACM code of ethics in decision making. Commun. ACM 36, 2 (1993), 98-107.

[2] Elliot Aronson et al. 1978. The jigsaw classroom. Sage.

[3] Robert J Beichner. 2014. History and evolution of active learning spaces. New Directions for Teaching and Learning 2014, 137 (2014), 9-16.

[4] Betty Collis and J Moonen. 2005. An on-going journey: Technology as a learning workbench. University of Twente (15 September 2005), 95.

[5] Tom Crick, Cathryn Knight, Richard Watermeyer, and Janet Goodall. 2020. The impact of COVID-19 and "Emergency Remote Teaching" on the UK computer science education community. In United Kingdom \& Ireland Computing Education Research conference. 31-37.

[6] Catherine H Crouch and Eric Mazur. 2001. Peer instruction: Ten years of experience and results. American journal of physics 69, 9 (2001), 970-977.

[7] Sarah Honeychurch. 2012. Taking forward the jigsaw classroom: the development and implementation of a method of collaborative learning for first year philosophy tutorials. Discourse: Learning and Teaching in Philosophical and Religious Studies 11, 2 (2012), 40-52.

[8] Aditi Kothiyal, Rwitajit Majumdar, Sahana Murthy, and Sridhar Iyer. 2013. Effect of think-pair-share in a large CS1 class: $83 \%$ sustained engagement. In Proceedings of the ninth annual international ACM conference on International computing education research. ACM, 137144.

[9] Soohyun Nam Liao, William G. Griswold, and Leo Porter. 2018. Classroom Experience Report on Jigsaw Learning. In Proceedings of the 23rd Annual ACM Conference on Innovation and Technology in Computer Science Education (ITiCSE 2018). ACM, New York, NY, USA, 302-307. https://doi.org/10.1145/3197091.3197118

[10] Joseph Maguire, Rosanne English, and Steve Draper. 2019. Data protection and privacy regulations as an inter-active-constructive practice. In Proceedings of the 3rd Conference on Computing Education Practice. $1-4$.

[11] Michael Prince. 2004. Does active learning work? A review of the research. Fournal of engineering education 93, 3 (2004), 223-231.

[12] Kate Sanders, Jonas Boustedt, Anna Eckerdal, Robert McCartney, and Carol Zander. 2017. Folk pedagogy: Nobody doesn't like active learning. In Proceedings of the 2017 ACM Conference on International Computing Education Research. ACM, New York, 145-154. 